\title{
Use and satisfaction of complementary and alternative medicine among diabetic patients in a tertiary care hospital
}

\author{
Monica N.*, Jayanthi CR, Praveen Panchaksharimath
}

\begin{abstract}
Department of Pharmacology, Bangalore medical college and Research Institute, Bangalore, Karnataka, India
\end{abstract}

Received: 27 August 2016 Accepted: 28 September 2016

*Correspondence to:

Dr. Monica N.,

Email: nmonica37@gmail.com

Copyright: (C) the author(s), publisher and licensee Medip Academy. This is an openaccess article distributed under the terms of the Creative Commons Attribution NonCommercial License, which permits unrestricted noncommercial use, distribution, and reproduction in any medium, provided the original work is properly cited.

\begin{abstract}
Background: Diabetes is a chronic disorder which requires long-term treatment. Non- adherence to treatment is a major factor responsible for morbidities and mortalities associated with diabetes. Complementary and alternative medicine (CAM) use has been one of the reasons for discontinuation of treatment. This study was conducted to assess the extent to which CAM and non-CAM users adhere to medical treatment.

Methods: 200 patients attending the diabetic clinic over a period of 2 months participated in the study. After obtaining written informed consent, they were administered a CAM use and satisfaction questionnaire (TSQM) based on effectiveness, no side-effects, convenience and global satisfaction.

Results: Out of 200 participants, 29\% (58) used CAM. Naturopathy was the most commonly followed type of CAM $(60 \% ; 35)$. Residing in the rural areas (OR-3.7), Socio- economic status above poverty line (OR-9), diabetics with comorbidities (OR-6) and microvascular complications (OR-6) and using insulin (OR-3) was found to be the predictors of CAM use. However, the incidence of hypoglycemic episodes was 52 times higher among CAM users. $(91 \%$; 52) of the CAM users did not reveal the use to their physicians, out of which $(70 \%$; 40) did not disclose due to the fear of discouragement by the doctor. CAM was found to be better in all aspects of patient satisfaction like effectiveness, noside-effects and global satisfaction than conventional medicine while conventional medicine users scored it to be more convenient to use than CAM. Conclusions: Doctors should enquire diabetics regarding CAM use since the voluntary disclosure is very less. Keeping lines of communication open for any discussions regarding pros and cons of CAM. Increasing patient awareness about potential drug interactions, when CAM is practised along with conventional medicine.
\end{abstract}

Keywords: Complementary and alternative medicine, Diabetes, TSQM

\section{INTRODUCTION}

Diabetes is a chronic debilitating medical condition that is fast gaining the status of a potential epidemic in India with more than 62 million diabetic individuals currently diagnosed with the disease. The prevalence is predicted to double globally from 171 million in 2000 to 366 million in 2030 with a maximum increase in India. ${ }^{1}$

Though allopathic medicines have shown to be of great value in treatment of diabetes, problems relating to drug non-compliance are as high as $75 \%$, owing to the exasperating multi-drug regimen, painful injections and the adverse effects profile. ${ }^{2,3}$

In India approximately $60 \%$ of the diabetic adults use Complementary and Alternative Medicine (CAM) as it complies with the cultural beliefs, and surmises it as appropriate to their illness. ${ }^{4-7}$ Although some CAM therapies have shown to be beneficial in controlling glycaemic levels, their clinical efficacy is controversial, as they lack scientific validation and safety unproven. ${ }^{8-10}$

Safety concerns have been raised regarding easy availability of Ayurvedic medicines sold online and as over the counter medicines. Toxicity due to heavy metals such as lead, mercury and arsenic are on the rise. Other concerns include use of herbs containing toxic compounds and lack of quality control in Ayurvedic facilities unlike for a pharmaceutical product to ensure quality, purity, efficacy and safety. Adverse effects of many CAMs are not well documented. ${ }^{11}$ 
Since diabetics are often on multiple medications due to their co-morbidities, the possibilities of herb-drug interaction or herb-dietary supplement interactions cannot be ruled out resulting in adverse drug reactions. ${ }^{9}$ This risk inflates, as at least $63 \%$ of CAM users do not disclose use of alternative methods to their physicians due to various reasons. $^{4-6}$

India has both, a high prevalence of diabetes and a long tradition of CAM use. However, there are limited research details on the use of CAM among diabetics in the southern part of India. Hence, this study was conducted to establish the prevalence of CAM use among diabetic patients and to evaluate the satisfaction of CAM users.

\section{METHODS}

This was a cross-sectional study carried out at Victoria and Bowring hospital attached to Bangalore medical college. Two hundred consenting outpatients with DM were recruited randomly for the study which took place over a period of 2 months (June - July 2016).

A minimum sample size of 185 was required based on a prevalence rate of $50-60 \%{ }^{[3]}$, obtained from previous research articles and power of $90 \%$. AYUSH and naturopathy were listed as CAM in the administered questionnaire.

Diabetics with minimum duration of the disease for at least a year were administered the questionnaire. Diabetics with disease duration less than a year were excluded to prevent bias.

A semi-structured Questionnaire pertaining to use and satisfaction of CAM was framed, which was pretested and validated by experts.

The questionnaire consisted of two parts: part I and part II pertaining to use and satisfaction respectively.

Part I consisted of 13 questions to assess sociodemographic and clinical characteristics, the use, pattern and reasons for use of CAM.

Part II consisted of TSQM (Treatment Satisfaction Questionnaire for Medication) version 7, which is a psychometrically sound and valid measure of the major dimensions of patient's satisfaction with medication. ${ }^{12}$ It consists of 14 questions, subdivided into 4 domainseffectiveness, side-effects, convenience and global satisfaction.

TSQM questions are scored on a seven point bipolar scale from 'extremely satisfied' to 'extremely dissatisfied' except question 4 which has a dichotomous response. Composite score is calculated for each domain by adding the scores of the questions. The lowest possible score is subtracted from the composite score and divided by (greatest possible score - lowest possible score). A transformed score between 0 and 1 is obtained, which is multiplied by 100 . The domain score ranges from 0 to 100 with higher scores representing higher satisfaction for that domain.

\section{Statistical analysis}

The prevalence of CAM users was determined and their socio- demographic and clinical characteristics assessed. The proportions of respondents using various forms of CAM were calculated.

Student's t test was used to compare the mean age and duration of DM in years between CAM and non CAM users. Chi square test was used to compare the sociodemographic and clinical characteristics of CAM users vs. non CAM users. The possible determinants of CAM usage were evaluated using a logistic regression model. CAM usage was entered in the model as the dependent variable and the independent variables included rural population, economical status, presence of complications and co-morbidities and insulin usage. This evaluation gave the $95 \%$ confidence intervals $(\mathrm{CI})$, Odds ratio (OR) and the $\mathrm{p}$ values.

The satisfaction of CAM and NCAM users was assessed using the TSQM scale. Satisfaction of the two treatment modalities were compared using the Kruskal- Wallis test.

\section{RESULTS}

\section{Demographic characteristics and CAM use}

A total of 200 patients consented to participate in the study, which included 96 females and 104 males, with a ratio of (1: 1.06), and mean age of $60.4 \pm 10.5$ years.

$45 \%$ were rural population and among them, $63 \%$ were below poverty line. 58 patients $(29 \%)$ were CAM users, while 142 patients $(71 \%)$ did not use CAM.

This study did not document any significant difference in CAM usage between males and females. However, CAM use was found to be more prevalent in the elderly population $(42 ; 73 \%)$ when compared to younger population $(16 ; 27 \%)$ with a statistical significance of 0.0057. Practice of CAM was more common among participants above poverty line $(42 ; 72 \%)$ compared with participants below poverty line $(16 ; 28 \%)$. This association was found to be statistically significant $(\mathrm{p}<0.0001)$. Our study revealed CAM to be more commonly preferred by rural population $(39 ; 67 \%)$ with urban: rural population ratio of 6:5 (Table 1).

\section{Clinical characteristics and CAM use}

The mean duration of diabetes in CAM and non-CAM users was comparable. $72 \%$ CAM users and $30 \%$ nonusers reported having at least one co-morbidity which 
included hypertension, ischemic heart disease or dyslipidemia. Presence of micro-vascular complications was comparable between the CAM users and non-users.
Of the CAM users, $48 \%$ were on oral hypoglycaemics alone and the remaining $52 \%$ received insulin as monotherapy or insulin plus oral hypoglycaemics.

Table 1: Demographic data.

\begin{tabular}{|c|c|c|c|c|c|}
\hline Characteristics & & $\begin{array}{l}\text { CAM } \\
58(29 \%)\end{array}$ & $\begin{array}{l}\text { NCAM } \\
142(71 \%)\end{array}$ & Significance & $\begin{array}{l}\text { OR ( } 95 \% \text { CI) for predictors of } \\
\text { CAM use }\end{array}$ \\
\hline Gender ${ }^{*}$ & $\begin{array}{l}\text { Males } \\
\text { Females }\end{array}$ & $\begin{array}{l}36(62 \%) \\
22(38 \%)\end{array}$ & $\begin{array}{l}68(48 \%) \\
74(52 \%)\end{array}$ & ns & \\
\hline Age $^{\#}$ (in years) & $(60.4 \pm 10.5)$ & $(61.6 \pm 9)$ & $(58.3 \pm 11)$ & $\begin{array}{l}\mathrm{P}=0.04 \\
(95 \% \text { CI } 1.6- \\
8.0)\end{array}$ & \\
\hline Residence ${ }^{* \&}$ & $\begin{array}{l}\text { Rural \& } \\
\text { Urban }\end{array}$ & $\begin{array}{l}39(67 \%)^{\&} \\
19(33 \%)\end{array}$ & $\begin{array}{l}50(35 \%)^{\&} \\
92(65 \%)\end{array}$ & $\mathrm{P}<0.0001$ & $3.7(1.9-7.2)$ \\
\hline $\begin{array}{l}\text { Socio-economic } \\
\text { status }{ }^{* \&}\end{array}$ & $\begin{array}{l}\mathrm{APL}^{\&} \\
\mathrm{BPL}\end{array}$ & $\begin{array}{l}42(72 \%)^{\&} \\
16(28 \%)\end{array}$ & $\begin{array}{l}32(23 \%)^{\&} \\
110(77 \%)\end{array}$ & $\mathrm{P}<0.0001$ & $9(4.4-18.1)$ \\
\hline
\end{tabular}

*Chi-square test, \#students t-test, BPL-below poverty line, APL- above poverty line, CAM-complementary Alternative Medicine, ns-

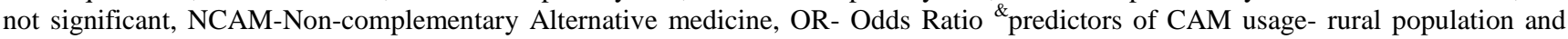
above poverty line. OR and $95 \%$ CI obtained by multivariate logistic regression test.

Table 2: Clinical characteristics.

\begin{tabular}{|c|c|c|c|c|c|}
\hline Characteristics & & $\begin{array}{l}\text { CAM } \\
\mathbf{N}(\%)\end{array}$ & $\begin{array}{l}\text { NCAM } \\
\mathbf{N}(\%)\end{array}$ & $\begin{array}{l}\text { Significance } \\
\text { (logistic } \\
\text { regression) }\end{array}$ & $\begin{array}{l}\text { OR }(95 \% \text { CI }) \text { for predictors of } \\
\text { CAM use }\end{array}$ \\
\hline $\begin{array}{l}\text { Duration of } \\
\text { diabetes\# }\end{array}$ & & $(7.2 \pm 5.2)$ & $(6.6 \pm 4.2)$ & $\mathrm{P}=0.3$ & \\
\hline $\begin{array}{l}\text { Treatment of } \\
\text { diabetes* }\end{array}$ & 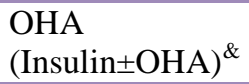 & $\begin{array}{l}28(48 \%) \\
30(52 \%)\end{array}$ & $\begin{array}{l}92(65 \%) \\
32(22.5 \%)\end{array}$ & $\mathrm{P}<0.0001$ & $3(1.9-7.0)$ \\
\hline $\begin{array}{l}\text { Co- } \\
\text { morbidities*\& }\end{array}$ & $\begin{array}{l}\text { Present } \\
\text { Absent }\end{array}$ & $\begin{array}{l}42(72.4 \%) \\
16(27.6 \%)\end{array}$ & $\begin{array}{l}43(30 \%) \\
99(70 \%)\end{array}$ & $\mathrm{P}<0.00001$ & $6(3.06-11.9)$ \\
\hline $\begin{array}{l}\text { Microvascular } \\
\text { complications } * \&\end{array}$ & $\begin{array}{l}\text { Present } \\
\text { Absent }\end{array}$ & $\begin{array}{l}15(25 \%) \\
43(75 \%)\end{array}$ & $\begin{array}{l}28(20 \%) \\
114(80 \%)\end{array}$ & $\mathrm{P}<0.309$ & $1.4(0.69-2.9)$ \\
\hline $\begin{array}{l}\text { Hypoglycemic } \\
\text { episodes }\end{array}$ & $\begin{array}{l}\text { Present } \\
\text { Absent }\end{array}$ & $\begin{array}{l}48(83 \%) \\
10(17 \%)\end{array}$ & $\begin{array}{l}12(8.45 \%) \\
130(92 \%)\end{array}$ & $\begin{array}{l}\text { (OR-52; } 95 \% \\
\text { CI, 21.7-128.0; } \\
\mathrm{P}=0.0000001)\end{array}$ & \\
\hline
\end{tabular}

*Chi square test, \#student's t-test, \$odds ratio, OHA-Oral Hypoglycemic Agents, OR- Odds Ratio, \&predictors of CAM usagetreatment with insulin, presence of co- morbidities and microvascular complications. OR and 95\% CI obtained by multivariate logistic regression test.

Table 3: Percentage of use of different CAMs.

\begin{tabular}{|ll|}
\hline CAM & Number of patients $(\%)$ \\
\hline Naturopathy & $35(60 \%)$ \\
\hline Yoga & $10(17.2 \%)$ \\
\hline Diet & $6(10.3 \%)$ \\
\hline Ayurveda & $5(8.6 \%)$ \\
\hline Homeopathy & $2(3.4 \%)$ \\
\hline
\end{tabular}

Overall, 60/200 patients (30\%) experienced hypoglycemia. CAM users experienced higher odds of hypoglycemic episodes with $48 / 58$ reporting of hypoglycemic symptoms (Table 2 ).

\section{Predictors of CAM usage}

The likelihood of rural population using CAM was thrice than that of urban population. People below poverty line were 9 times less likely to follow CAM. Similarly, those with no co-morbidities were less likely to use CAM. Although logistic regression evaluation for presence of complications showed high odds ratio value, there was no statistical significance $(\mathrm{p}<0.3)$ (Table 2).

\section{Type of CAM use}

Majority used naturopathy $(60 \%)$ followed by yoga $(17 \%)$. Desire for quick and additional relief was the most common reason stated for using CAM, as reported 
by $86 \%$ users (Figure 1). Easy availability was the reason for use, reported by $52 \%$ users. Only $60 \%$ of the population followed CAM on a regular basis. All of the CAM users used CAM along with conventional medicine (Table 3).

\section{Disclosure of CAM use to physician}

Only 6 CAM users (9\%) had admitted using CAM to their physicians while a majority $91 \%$ did not disclose. The most common reason stated for not revealing CAM use to their physician was that they feared discouragement by doctors $(70 \%)$, while $50 \%$ of CAM users did not feel it was necessary to inform as they thought CAMs were totally safe to be used with conventional medicines (Figure 2, 3).

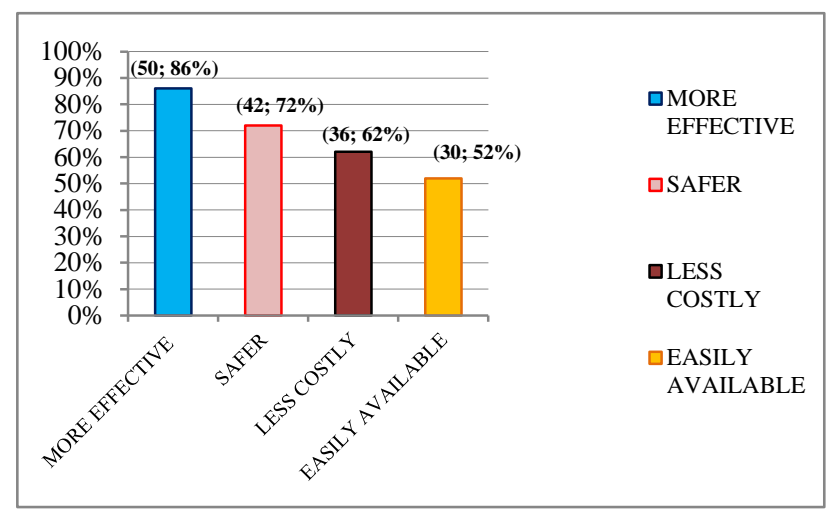

Figure 1: Reasons for CAM use.

\section{Satisfaction with CAM}

CAM scored better in the domains of effectiveness (70.42 vs. 63.42) and safety (98.12 vs. 66.16) when compared to use of only conventional medicine. This difference was found to be statistically significant with a $\mathrm{p}$ value of 0.001 and 0.0005 respectively. Convenience was scored better by conventional medicine when compared to CAM with a score of 90.42 and 70.62 respectively, with a statistical significance of 0.002. Overall, global satisfaction score for CAM was higher than conventional medicine with a statistical significance of 0.0002 (Table 4, Figure 4).

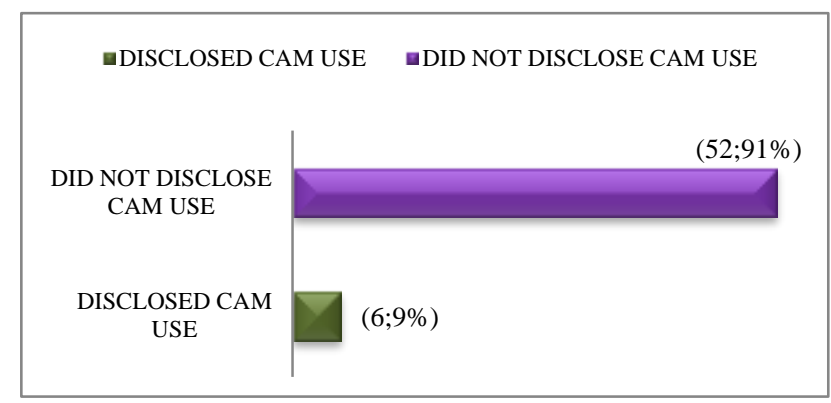

Figure 2: Rate of CAM disclosure by patients to their physician.

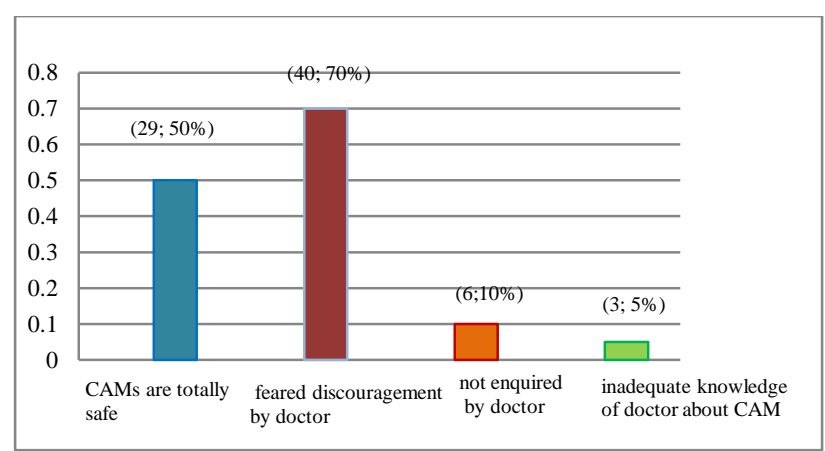

Figure 3: Reasons for non-disclosure of CAM use to physician.

Table 3: Patient's satisfaction with CAM and NCAM.

\begin{tabular}{|llll|}
\hline Domain & CAM & NCAM & Significance* \\
\hline Effectiveness & 70.42 & 63.42 & $<0.001$ \\
\hline $\begin{array}{l}\text { No side- } \\
\text { effects }\end{array}$ & 98.12 & 66.16 & $<0.0005$ \\
\hline Convenience & 70.62 & 90.42 & $<0.002$ \\
\hline $\begin{array}{l}\text { Global } \\
\text { satisfaction }\end{array}$ & 80.76 & 70.42 & $<0.0002$ \\
\hline
\end{tabular}

*Significance tested by Kruskal-Wallis test.

\section{DISCUSSION}

Alternative medicines are of special interest in combination with conventional medicines because of their different modes of action. ${ }^{13}$ Some researchers have found the increasing popularity of CAM among patients of chronic diseases due to the belief among them about the perceived limitations of the medical paradigm and the apparent failure of conventional medicine to treat and/or cure chronic illnesses and catastrophic diseases. ${ }^{14}$ Since diabetes is a chronic disorder with the effectiveness of the treatment depending on the compliance of the patient to the treatment, factors affecting their adherence matters. CAM was found to be one of the factors affecting adherence to conventional medicine which is associated with adherence to conventional treatment, this study was conducted and our study aimed at assessing the extent of treatment adherence among CAM users when compared to non- CAM users.

A prevalence rate of $29 \%$ CAM use in diabetics was observed in the present study. This was much lesser than other similar studies conducted by Kumar et al in Allahabad, Roy V et al., in New Delhi and Bhalerao et al., in Mumbai which showed an approximate 65\% CAM use. $^{4,6,9}$ This indirectly indicates an increased acceptance of conventional medicine over CAM. Also, the observed variations in CAM use by geographic region could be in part attributed to differences in socio- cultural perceptions of CAM use and to disparities in the availability and access to conventional medicines.

$55 \%$ of our respondents were from urban population, despite which, we documented a whopping $67 \%$ of the 
CAM users to have a rural background. This is consistent with results obtained from a study conducted by Arcury et al. ${ }^{15}$ People in the rural areas tend to have higher faith in traditional medicine than those from urban areas, as it is a part of their cultural belief and also has a holistic approach.

Though our study found that those with complications (25\%) were using CAM more frequently than those without complications (20\%), this association was found to be statistically insignificant. A study conducted by Khalaf et al., in Bahrain and Bhalerao et al., in India also showed that approximately $73 \%$ of the diabetics with complications used CAM, which was found to be statistically significant. ${ }^{6,16}$ The statistical insignificance in our study may be explained by a smaller sample size, along with a smaller percentage of CAM users (29\%). This relation between CAM use and presence of complications might probably be because patients try different modalities of therapy to overcome diseases of longer duration.

Our study documented a high association between presence of co-morbidities and usage of CAM with $72.4 \%$ of CAM users having co- morbidities. This result was supported by a similar study done by Gor et al., where diabetics with hypertension were more prone to follow CAM when compared to those without hypertension. $^{17}$ Patients may resort to using CAM therapies on an alternative or complementary basis due to their fatigue, despair with conventional therapies, to save costs or to try something new. Furthermore, patients seek alternative therapies as they seem less authoritarian and more empowering and offer personal autonomy.

Our study showed that the likelihood of insulin users preferring CAM were 3 times higher than non-insulin users. This result was parallel to a study conducted in Nigeria by Ogbera et al. ${ }^{18}$ Patients resort to CAM use due to three main reasons which are, pain and dissatisfaction associated with the use of insulin therapy, to cut down on dose and frequency of insulin or aiding in changeover to oral medications and lastly due to affordability issues.

Hypoglycemic episodes occurring as a secondary consequence was considered as presence of symptoms like sweating, palpitations, giddiness, hunger, confusion, loss of consciousness or seizures which relieved following carbohydrate intake. The odds of occurrence of hypoglycemic episodes were 52 times higher among CAM using diabetics when compared to those not using CAM. Similar results were obtained in a study which was conducted by Medagama AB, in Srilanka and Singh et al., in India. ${ }^{19,20}$ This might be possibly due to the interplay of various factors like drug- herb interaction, drug-food interactions among ayurvedic and naturopathy users respectively. However, those who practiced yoga reported a better sense of well-being and fewer episodes of hypoglycemia.
CAM therapies yielded a better 'perceived relief' to their users when compared with conventional medicine users. Global satisfaction (80.76 vs. 70.42$)$ was highest in the CAM using group. This probably seems to be related to psychologically positive attitude of the patients towards CAM. However, convenience scores were higher in the conventional medicine users group (90.42 vs. 70.62) since most of our CAM users followed naturopathy which is time consuming when compared to readily to administer oral hypoglycemics.

While a study conducted by Roy $\mathrm{V}$ et al., found that diabetic patients followed Ayurveda more commonly, the studies conducted by Kumar et al., and Bhalerao et al., found that naturopathy was the most commonly followed CAM with a use of $97.3 \%$ and $44 \%$ respectively. ${ }^{4,6,9}$ Our study also documented the latter, with $60 \%$ of them following naturopathy.

This might be attributed to the fact that most of the study population falls below poverty line making it impossible for them to access alternative therapies like Ayurveda and homeopathy. Hence, accessibility and affordability might be the major factor which decides the type of CAM usage

Though CAM users reported that CAM was sufficiently effective in reducing their glycemic levels, none of them were reported with supporting evidences that it was solely due to use of CAM. Though CAM users reported that CAM did not cause any side-effects when compared to conventional medicine, our study reported higher incidences of hypoglycemia among CAM users. This mismatch may be due to the misconception that CAMs are totally safe. Overall, satisfaction of CAM users was significantly better than NCAM users. However, they also said that it was inconvenient to follow them regularly, while it was easy to use conventional medicines.

$91 \%$ of the CAM users reported that their treating physicians were not aware of their patients using CAM concomitantly with conventional medicine. This was due to the fear that the treating physician might criticize CAM use $(70 \%)$ resulting in a hampered patient- doctor relationship, misconception that CAM is totally safe $(50 \%)$. This was indistinguishable from other studies reporting the same. ${ }^{4-6}$ Patients using naturopathy did not feel it was necessary to inform the physician as they were unaware of the possible hazardous outcomes. Hence, there is a need for health care providers to keep lines of communication open for free discussion of this aspect of management with their patients.

Clinicians should also explore CAM practices used by their patients in order to avoid misleading clinical decisions and educate patients about the possible drug interactions. The unsupervised use of these CAM modalities with conventional medicines bears the risk of CAM-drug interactions which may compromise the optimal management of diabetes. Further community- 
based studies are needed to investigate the actual usage pattern of patients not attending for allopathic treatment. Increasing the awareness in patients regarding spacing of minimum two hours between the concomitantly used medications and encouraging patients to continue conventional medicines and preventing discontinuation is a fact that has to be stressed on.

Hypoglycemia as reported by the patients were based on the symptoms rather than being based on biochemical values, non-availability of $\mathrm{HbA}_{1} \mathrm{c}$ measurements, and a small sample size are identified as limitations in this study.

Scoring of satisfaction was subjective since clinical efficacy of CAM was not measured by lab parameters. This needs to be supported with scientific evidence of better reduction of blood glucose in patients using CAM plus conventional medicine.

\section{CONCLUSION}

People with Type 2 diabetes in South India are likely to use both conventional medicine and CAM in managing their illness without appropriate information sources to support their decision. Physicians need to enquire about CAM use specifically since a large number of them do not feel the necessity to inform their physicians. This might help in reducing complications that might result due to concomitant use of two different modalities of treatment. Before CAM can be introduced into the healthcare system, these therapies should be tested for dosage, contaminants, bioavailability and costeffectiveness.

Funding: No funding sources Conflict of interest: None declared

Ethical approval: The study was approved by the Institutional Ethics Committee

\section{REFERENCES}

1. Kaveeshwar S. The current status of diabetes mellitus in India. Australasian Medical Journal. 2014;7(1):458.

2. Shobhana R, Begum R, Snehalatha C, Vijay V, Ramachandran A. Patients' adherence to diabetes treatment. J Assoc Physicians India. 1999;47:1173-5.

3. Khan A, Al-Abdul Lateef Z, Al Aithan M, BuKhamseen M, Al Ibrahim I, Khan S. Factors contributing to non- compliance among diabetics attending primary health centers in the Al Hasa district of Saudi Arabia. J Fam Community Med. 2012;19(1):26.

4. Roy V, Gupta M, Ghosh R. Perception, attitude and usage of complementary and alternative medicine among doctors and patients in a tertiary care hospital in India. Indian Journal of Pharmacology. 2015;47(2):137.
5. Apurva Agrawal A. Complementary and alternative medicine (CAM) use among patients presenting in out- patient department at a tertiary care teaching hospital in Southern Rajasthan, India- A Questionniare based study. Altern Integ Med. 2015;04(01).

6. Bhalerao MS, Bolshete PM, Swar BD, Bangera TA, Kohle VR, et al. Use of and satisfaction with complementary and alternative medicine in four chronic diseases: a cross sectional study from India. Natl Med J India. 2013;26:75-8.

7. Astin JA. Why patients use alternative medicine: Results of a national study. JAMA. 1998;279:154853.

8. Yeh GY, Eisenberg DM. Systematic review of herbs and dietary supplements for glycemic control in diabetes. Diabetes Care. 2003;26(4):1277-94.

9. Birdee G, Yeh G. Complementary and alternative medicine therapies for diabetes: A clinical review. Clinical diabetes. 2010;28(4):147-55.

10. Kinsel JF, Straus SE. Complementary and alternative therapeutics: Rigorous research is needed to support claims. Annu Rev Pharmacol Toxicol. 2003;43:46384.

11. Saper RB, Phillips RS, Sehgal A, Khouri N, Davis RB, Paquin J, et al. Lead, mercury, and arsenic in USand Indian manufactured Ayurvedic medicines sold via the Internet. JAMA. 2008;300:915-23.

12. Atkinson MJ, Sinha A, Hass SL, Colman SS, Kumar $\mathrm{RN}$, Brod M et al . Validation of a general measure of treatment satisfaction, the Treatment Satisfaction Questionnaire for Medication (TSQM), using a national panel study of chronic disease. biomed central. 2004;2(12):1-13.

13. De Smet PA. Herbal Remedies. N Eng J Med. 2002;347:2046-56.

14. Hiromi Kobayashi, Kuniaki Takahashi, Nobuyuki Mizuno, Haruo Kutsuna, Masamitsu Ishii. An Alternative Approach to Atopic Dermatitis: Part IISummary of Cases and Discussion. Evid Based Complement Alternat Med 2004 ; 1: 145-55.

15. Arcury T, Bell R, Snively B,Smith S, Skelly A, Wetmore L, et al. Complementary and alternative medicine use as health self management: rural older adults with diabetes. The journal of gerontology series B: psychological sciences and social sciences. 2006;61(2):S62-70.

16. Khalaf A Whitford D. The use of Complementary and alternative medicine by patients with diabetes mellitus in Bahrain: A cross-sectional study. BMC Complementary and alternative medicine. 2010;10(1):35.

17. Gor A, Kothari N, Shah P, Gaur K. Use of complementary and alternative medicine (CAM) in patients with essential hypertension and diabetes mellitus attending a tertiary care teaching hospital. Inter Jou Med Sci Dent Heal. 2015;1(2):50-7.

18. Ogbera A, Dada O, Adeley F, Jewo P. Complementary and alternative medicine use in 
diabetes mellitus. West African Journal of Medicine. 2011;29(3).

19. Medagama A, Bandara R, Abeysekara R, Imbulpitiya B, Pushpakumari T. Use of Complementary and alternative medicines(CAMs) among type 2 diabetes patients in Srilanka: A cross- sectional survey: BMC
Complementary and alternative medicine. 2014;14(1):374.

20. Singh. Self medication with herbal remedies amongst patients of type 2 diabetes mellitus: a preliminary study. Indian Journal of endocrinology and metabolism. 2012;16(4).

Cite this article as: Monica N., Jayanthi CR, Praveen P. Use and satisfaction of complementary and alternative medicine among diabetic patients in a tertiary care hospital. Int J Basic Clin Pharmacol 2016;5:2521-7. 